\title{
Nurses Experience in End of Life Decision-Making for Covid-19 Patients in the Intensive Care Unit
}

\author{
Diah Tika Anggraeni ${ }^{1 *}$, Deby Tangkabiringan ${ }^{2}$ Mareta Dea Rosaline ${ }^{1}$
}

\author{
${ }^{1}$ Nursing Program, Faculty of Health Science, Universitas Pembangunan Nasional Veteran Jakarta, Jakarta \\ ${ }^{2}$ Kandou Hospital, Manado \\ *Corresponding author. Email: diahtika@upnvj.ac.id
}

\begin{abstract}
Background: COVID-19 virus spread rapidly throughout the world. It caused the massive patients admitted to the hospitals with severe Acute Respiratory Distress Syndrome to exceed the capacity of beds in the ICU. It makes the hospital give priority to the ICU bed for the COVID-19 patient with the best prognosis or the decision to accelerate the withdrawal of life support. During this situation, pay attention for end of life decision-making in the ICU was important. The aim is to identify nurses' experiences in the intensive care unit regarding the involvement and expected outcome assessment in end-of-life care decision making in the Intensive care unit. Method: The research method of the study was a descriptive study using a questionnaire in the Google form. Results: The results showed that end of life decisions regarding withdrawal and withholding life support in COVID-19 patients based on several important consideration, including the ability to survive life $(63,2 \%)$, neurological status $(63,2 \%)$, and quality of life $(86,8 \%)$ of patients after receiving treatment in the ICU. Furthermore, nurses are always actively involved in the goals of the care plan $(60,5 \%)$ and considering the end of life decisions. This involvement affects job satisfaction (73,7\%). A family member of COVID-19 patient is always involved in end of life discussions $(76,3 \%)$. Conclusion: Our study indicates that end of life decisions regarding withdrawal and withholding life support in COVID-19 patients in the ICU are based on several considerations. The nurse is always actively involved in setting goals of care and facilitated family member in these decisions. The recommendation for future research is identifying the type of effective communication technologies and media to facilitate family members at the end of life process during the COVID-19 pandemic.
\end{abstract}

Keywords: COVID-19, End of life, Intensive Care Unit, Nurses experience

\section{INTRODUCTION}

COVID-19 cases were first reported in December 2019 in China. The virus spread rapidly throughout the world. Therefore, on January 30, 2020, the World Health Organization (WHO) declared COVID-19 is a public health emergency of international concern and in the first week of March, COVID-19 has declared a pandemic [1]. The COVID-

19 pandemic that has hit the whole world has caused the number of patients admitted to hospitals with severe ARDS to exceed the capacity of the number of beds in the ICU. Therefore, several institutions are reviewing the goals of care for COVID-19 patients in the ICU [2]. One of these goals is the priority of the ICU bed for the patient with the best prognosis or the decision to accelerate the withdrawal of life support [3]. Several considerations that need to be considered during the COVID-19 pandemic are the priorities of patients who are most likely to survive the disease they have [4]. In addition, patient priority was also identified from the possibility of living longer after recovery by considering comorbidities [2] [4].
Grasselli et al (2020) and the Centers for Disease Control and Prevention (2020) show that approximately $16 \%-24 \%$ of patients infected with COVID-19 require ICU care [5] [6]. Of these patients, more than $60 \%$ of COVID-19 patients who require mechanical ventilation support do not survive [7]. Therefore, Jackson et al (2020) stated that the COVID-

19 pandemic resulted in a 'tsunami' of death due to the high mortality rate of COVID-19 patients [8].

During this pandemic, the risk of ethical lapses due to massive admissions, limited patient beds, and missed opportunities for patients to receive mechanical ventilation support can occur [2]. In addition, WHO recommends limiting family visits of COVID-19 patients to prevent the spread of this disease. This is a challenge for principle care in the ICU focused on family- centered care.

An issue that is rarely discussed, but important is the need for end-of-life care resources in intensive rooms to ensure symptom management and comfort for COVID-19 patients during the dying process [9]. The 
involvement of nurses as caregivers and advocators in end-of-life care for patients is certainly an important component to identify. Therefore, this study aims to identify nurses' experiences in the intensive care unit regarding the involvement and expected outcome assessment in end-of-life care decision making in the Intensive care unit.

\section{METHOD}

The study was a descriptive study using a questionnaire in the Google form. We used a convenience sample with inclusion criteria was a critical care nurse who cares for COVID-19 patients in the ICU. The questionnaire was a modification from the end of life questionnaire developed by Latour et al (2009) [10]. The questionnaire composed of three sections, section 1 was demographic data; section 2 about expected outcome assessment; section 3 contains the experience of critical care nurses at the end of life of COVID-19 patient. A 5-point Likert scale was used for sections 1 and 2. Data were analysed using SPSS. The descriptive statistic and non-parametric tests were applied because all data were in the ordinal category.

\section{RESULT}

As indicated above, the researchers were successful in collecting 38 responses which have filled the questionnaire. All respondents filled out all the questions in the questionnaire. Table 1 describes the demographic characteristics of the respondents including gender, age, level of education, religious background, and years of experience in the ICU. Based on the distribution, the female critical care nurses more than male at $60,5 \%$ and $39 ., 5 \%$ respectively. The highest age of the respondents is under 30 years old $(73,7 \%)$ followed by the age of 30-39 years old $(15,8 \%)$. Furthermore, the majority level of education is a bachelor of nursing $(55,3 \%)$ with a religious background who is protestant $(60,5 \%)$. For years of experience in the ICU, the majority of respondents have been critical care nurses for $0-5$ years.

Table 1. Characteristic of respondents $(n=38)$

\begin{tabular}{|c|c|}
\hline Characteristic & $\mathrm{n}(\%)$ \\
\hline \multicolumn{2}{|l|}{ Gender } \\
\hline Male & $5(39,5)$ \\
\hline Female & $23(60,5)$ \\
\hline \multicolumn{2}{|l|}{ Age } \\
\hline$<30$ years & $28(73,7)$ \\
\hline $30-39$ years & $6(15,8)$ \\
\hline $40-49$ years & $4(10,5)$ \\
\hline \multicolumn{2}{|c|}{ Level of education } \\
\hline Diploma & $14(36,8)$ \\
\hline \multicolumn{2}{|c|}{ Bachelor of nursing $21(55,3)$} \\
\hline Master of nursing & $\mathrm{g} \quad 3(7,9)$ \\
\hline \multicolumn{2}{|c|}{ Religious background } \\
\hline Islam $\quad 9$ & $(23,7)$ \\
\hline Protestant & $23(60,5)$ \\
\hline Chatolic & $5(13,2)$ \\
\hline Hindu $\quad 1$ & $1(2,6)$ \\
\hline \multicolumn{2}{|c|}{ Years of experience in ICU } \\
\hline $0-5$ years & $31(81,6)$ \\
\hline $6-10$ years & $3(7,9)$ \\
\hline $11-15$ ears & $3(7,9)$ \\
\hline$>15$ years & $1(2,6)$ \\
\hline
\end{tabular}

One of the considerations in end-of-life decisions making is the assessment of the expected outcomes of COVID-19 patients. Table 2 shows that the decision of whether COVID-19 patients cannot survive despite receiving ICU care is an important consideration in withholding and withdrawing life support $(63.2 \%)$. In addition, the consideration that if COVID-19 patients can survive, but the patient's neurological status will be very poor $(63.2 \%)$, and the patient's quality of life will be very poor $(86.8 \%)$ were the expected outcome that is important in the final decision making of end of life.

Table 2. Expected Outcome Assessment of COVID-19 Patients

\begin{tabular}{lccc}
\hline & $\begin{array}{c}\text { Very important or important } \\
\mathrm{n}(\%)\end{array}$ & $\begin{array}{c}\text { Not sure } \\
\mathrm{n}(\%)\end{array}$ & $\begin{array}{c}\text { Quite important or not } \\
\text { important } \\
\mathrm{n}(\%)\end{array}$ \\
\hline $\begin{array}{l}\text { The COVID-19 patient is unlikely } \\
\text { to survive despite intensive care } \\
\text { treatment }\end{array}$ & $24(63,2)$ & $9(23,7)$ & $5(13,1)$ \\
\hline $\begin{array}{l}\text { If the COVID-19 patient does } \\
\text { survive, the neurological outcome } \\
\text { is very poor }\end{array}$ & $24(63,2)$ & $7(18,4)$ & $7(18,4)$ \\
\hline $\begin{array}{l}\text { If the COVID-19 patient does } \\
\text { survive, their quality of life is very } \\
\text { poor }\end{array}$ & $33(86,8)$ & $4(10,6)$ & $1(2,6)$ \\
\hline
\end{tabular}


The experience of nurses at the end of life of COVID-19 patients (table 3) shows that the time to discuss between nurses, doctors, and patients' families about end of life in the ICU is done on time (71\%). In addition, $55.2 \%$ of nurses were asked by doctors to participate in withhold and withdrawal life support decision making in the ICU. As many as $60.5 \%$ of nurses are also actively involved in discussions about end of life, even $52 \%$ of nurses often initiate discussions about the end of life of COVID-19 patients in the ICU with the physician. The involvement of nurses in the decision-making of end-of-life for COVID-19 patients actually affects job satisfaction as critical care nurses.

Although during the COVID-19 pandemic, the patient's family was always involved in making the end of life decisions (76.3\%). In addition, family consultation is always facilitated by nurses and physician before end of life decision making (86.8\%).

Table 3.Nurses experiences in End of life care of COVID-19 patient

\begin{tabular}{|c|c|c|c|}
\hline & $\begin{array}{l}\text { Strongly disagree } \\
\text { or disagree }\end{array}$ & $\begin{array}{l}\text { Not sure } \\
\mathrm{n}(\%)\end{array}$ & $\begin{array}{c}\text { Agree or } \\
\text { strongly agree }\end{array}$ \\
\hline & $\mathrm{n}(\%)$ & & \\
\hline $\begin{array}{l}\text { Timing of End of life care discussion } \\
\text { for COVID-19 in the ICU too early }\end{array}$ & $13(34,2)$ & $14(36,8)$ & $11(29)$ \\
\hline $\begin{array}{l}\text { Timing of End of life care discussion } \\
\text { for COVID-19 in the ICU just right }\end{array}$ & $2(5,3)$ & $9(23,7)$ & $27(71)$ \\
\hline $\begin{array}{l}\text { Timing of End of life discussion for } \\
\text { COVID-19 in the ICU too late }\end{array}$ & $20(52,6)$ & $15(39,5)$ & $3(7,9)$ \\
\hline $\begin{array}{l}\text { Asked by medical colleagues to } \\
\text { participate in end of life decisions for } \\
\text { COVID-19 }\end{array}$ & $10(26,4)$ & $7(18,4)$ & $21(55,2)$ \\
\hline $\begin{array}{l}\text { Always actively involved in end of life } \\
\text { discussion with physicians for COVID- } \\
19\end{array}$ & $6(15,8)$ & $9(23,7)$ & $23(60,5)$ \\
\hline $\begin{array}{l}\text { Often initiated end of life discussion for } \\
\text { COVID-19 with doctors }\end{array}$ & $6(15,8)$ & $12(31,6)$ & $20(52,6)$ \\
\hline $\begin{array}{l}\text { Family of COVID-19 patient is always } \\
\text { involved in end of life discussions }\end{array}$ & $3(7,9)$ & $6(15,8)$ & $29(76,3)$ \\
\hline $\begin{array}{l}\text { Family of COVID-19 always need to be } \\
\text { consulted before End of life decisions is } \\
\text { made }\end{array}$ & $2(5,3)$ & $3(7,9)$ & $33(86,8)$ \\
\hline $\begin{array}{l}\text { Involvement in end of life decisions for } \\
\text { COVID-19 positively influences job } \\
\text { satisfaction }\end{array}$ & $4(10,5)$ & $6(15,8)$ & $28 \quad(73,7)$ \\
\hline
\end{tabular}

\section{DISCUSSION}

Limited bed capacity in the ICU makes health workers, especially doctors and nurses face challenges in the process of withholding and withdrawing patient life support [8]. End of life care plans is carried out in collaboration between patients, families, physician, and other medical teams. Latour, Fulbrook \& Albarran (2009) state that end of life care is supportive care and services for patients with severe illness or trauma, where the patient's family decides to withdraw or withhold the patient's treatment and life support. Withdraw treatment is a decision that is planned to stop the treatment that has been given, whereas withhold is a decision that is planned not to start treatment for the patient [10] [11].

Our study indicates that one of the considerations used for decision making in end of life care is an assessment of whether COVID-19 patients can survive if they are given care in the ICU. In addition, assessment of the possible outcomes of the neurological status and quality of life of COVID19 patients is also an important consideration in withholding and withdrawal life support. The results are supported by Latour, Fulbrook \& Albarran (2009) that the consideration of a patient to survive despite receiving ICU treatment is an important assessment in making withhold and withdrawal decisions [10].

COVID-19 has been shown to be a deadly disease, especially in certain patient groups, carrying a mortality rate of $14.8 \%$ in the elderly and higher in those with serious comorbidities and frailties [12] [13]. Schiffrin et al (2020) added that elderly patients and patients with comorbid diabetes mellitus, hypertension, coronary heart disease, and cerebrovascular disease have a greater 
risk of worsening the condition than young patients without the comorbid disease [14]. This becomes the ethical value in the consideration of prioritizing patient care support in the ICU [4].

White \& Lo (2020) stated that the assessment of the severity of patients in the ICU needs to be carried out continuously so that the decision to withdraw support from mechanical ventilation in one patient can be beneficial for other patients [15]. Different from the research result of Yaguchi et al (2005) which states that doctors rarely involve nurses in making the end of life decisions, the results of this study indicate that

$55.2 \%$ of nurses are asked by physicians in decision making [16]. Furthermore, $52.6 \%$ of nurses often initiated the end of life discussion with physicians, and $73.7 \%$ of nurses said that involvement in end of life decision for COVID-19 patients positively influences their job satisfaction. This is an important component given the importance of setting goals for patient care during this pandemic [9].

Our results also showed that $71 \%$ of nurses stated that discussions about end of life care in COVID-19 patients were carried out on time. Robert et al (2020) stated that the delayed end of life decision making risks causing increased mortality due to lack of beds in the ICU [2]. Mottiar (2020) added that the principle of discussion in end of life care is the assessment of disease and its complications, decision making, and recommendations for patient treatment plans [17]. Robert et al (2020) stated that decision making was a very important element during this pandemic emergency. One of the considerations in making this decision is to provide a bed for COVID-19 patients who have a greater chance of living at the expense of other patients without improvement. However, it needs to be balanced with the consideration of extending the patient's care in the ICU with the hope of greater improvement of the patient's condition [2]. Therefore, the decision- making process regarding mechanical ventilation withdrawal support in this pandemic situation is very complex.

Apart from the complexity of decisionmaking, visit restrictions imposed on the family members are also a challenge in this pandemic situation. Arya et al (2020) stated that restrictions on family visits can affect communication skills that nurses are used to and can cause stress that affects the discussion objectives of treating COVID-19 patients in the ICU [9]. The results of this study indicate that even in a pandemic situation and visit restrictions, $76.3 \%$ of nurses stated that the families of COVID-19 patients are always involved at every end of life discussion with doctors and nurses. Furthermore, $86.8 \%$ of nurses also stated that family members of COVID-19 always need to be consulted before end of life decisions is made. Robert et al (2020) emphasize that communication is an important aspect of the current situation, especially communication in decision-making and the patient's dying process. Therefore, decision making with family was compromised because it is harmful to both patients and family members [2].

Nurses should still pay attention to the therapeutic relationship in communication when making decisions [18]. This is because the experience of family members who are dissatisfied with the information provided during the patient's care can lead to the post-ICU syndrome in family members (PICS-F) [19]. Nelson et al (2010) added that communication in family member involvement and a consistent consultation process can prevent the occurrence of PICS-F or Post Traumatic Stress Disorder (PTSD) after grief [20]. During the COVID-19 pandemic, Hart et al (2020) recommend direct communication with family members of patients via telephone or institutional websites regarding the purpose of the visit restrictions imposed. It is important for them to understand why they cannot visit their loved ones. In addition, scheduling routine communication with family members via telephone is one solution to maintain communication continuity while COVID-19 patients are treated in the ICU [21].

\section{CONCLUSION}

Our study indicates that end of life decisions regarding withdrawal and withholding life support in COVID-19 patients in the ICU are based on several considerations including survival, neurological status, and quality of life of patients after receiving treatment in the ICU. In addition, families are always involved in making these decisions even though they are limited to visits to the hospital. The nurse, as a patient caregiver and advocator, is always actively involved in setting care goals and considering the end of life decisions. This involvement turned out to affect the job satisfaction of nurses in the ICU room. This may occur because the decision to withdraw support from mechanical ventilation in one patient can be beneficial for other patients due to the massive number of COVID-19 patients during this pandemic. Therefore, nurses in the intensive care unit should still pay attention to therapeutic communication with the patient's family even though communication may be done via telephone 
or video conference. Scheduling regular consultations may be a solution for smooth communication in the decision-making process. The recommendation for future research is identify the type of effective communication technique and media to facilitate family member in end of life process during the COVID-19 pandemic.

\section{REFERENCES}

[1] World Health Organization. https://apps.who.int/iris/bitstream/handle/10665/ 331695/WHO-2019-nCov-IPC PPE use-2020.3eng.pdf, 2020 (Accessed August 2020)

[2] Robert R, Kentish-Barnes N, Boyer A, Laurent A, Azoulay E, Reignier J. Ethical dilemmas due to the Covid-19 pandemic. Annals of intensive care. 2020 Dec;10(1):1-9.

[3] Davidson JE, Aslakson RA, Long AC, Puntillo KA, Kross EK, Hart J, et al.Guidelines for family-centered care in the neonatal, pediatric, and adult ICU. Crit Care Med. 2017;45(1):103-28.

[4] Brown MJ, Goodwin J, Liddell K, Martin S, Palmer S, Firth P, Eyal N, Hyder A, Persad G, Phillips J, Emanuel E. Allocating medical resources in the time of Covid-19. N Engl J Med. 2020.DOI: https ://doi.org/10.1056/NEJMc 2009666

[5] Giacomo G, Antonio P, Maurizio C. Critical Care Utilization for the COVID-19 Outbreak in Lombardy, Italy. JAMA. 2020;323(16):1545. DOI : http://dx.doi.org/10.1001/jama.2020.4031

[6] Centers for Disease Control and Prevention. Morbidity and Mortality Weekly Reports. Severe Outcomes Among Patients with Coronavirus Disease 2019 (COVID-19) - United States,2020

[7] Intensive Care National Audit \& Research Centre. https://www.icnarc.org/Our-

Audit/Audits/Cmp/Reports,2020 (Accessed September 2020)

[8] Jackson, D., Bradbury-Jones, C., Baptiste, D., Gelling, L., Morin, K., Neville, S., \& Smith, G. D. Life in the pandemic: Some reflections on nursing in the context of COVID-19. Journal of clinical nursing.2020.DOI:http://dx.doi.org/10.1111/jocn.1525 7

[9]Arya A, Buchman S, Gagnon B, Downar J. Pandemic palliative care: beyond ventilators and saving lives. CMAJ 2020.2 DOI: https://doi.org/10.1503/cmaj.200465

[10] Latour JM, Fulbrook P, Albarran JW. EfCCNa survey: European intensive care nurses' attitudes and beliefs towards end-of-life care. Nursing in critical care. 2009 May;14(3):110-21.
[11] Hall RI, Rocker GM. End-of-life care in the ICU: treatments provided when life support was or was not withdrawn. Chest. 2000 Nov 1;118(5):1424-30.

[12] National Institute for Health and Care Excellence. COVID-19 rapid guideline: critical care in adults. Available from URL: https://www.nice.org.uk/guidance/ng159 (accessed August 2020).

[13] Fang L, Karakiulakis G, Roth M. Are patients with hypertension and diabetes mellitus at increased risk for COVID-19 infection?. The Lancet. Respiratory Medicine. 2020 Apr;8(4):e21.

[14] Schiffrin EL, Flack JM, Ito S, Muntner P, Webb RC. Hypertension and COVID-19,2020 May 33(5):373-374.

[15] White DB, Lo B. A framework for rationing ventilators and critical care beds during the COVID-19 pandemic. JAMA. 2020;323:1773-4. https :// doi.org/10.1001/jama.2020.5046

[16] Yaguchi A, Truog RD, Curtis JR, Luce JM, Levy MM, Mélot C, Vincent JL. International differences in end-of-life attitudes in the intensive care unit: results of a survey. Archives of internal medicine. $2005 \mathrm{Sep}$ 26;165(17):1970-5.

[17] Mottiar M, Hendin A, Fischer L, des Ordons AR, Hartwick M. End-of-life care in patients with a highly transmissible respiratory virus: implications for COVID-19. Canadian Journal of Anaesthesia. 2020 May 11:1.

[18] Roze des Ordons, A, Vanderspank B, Hartwick M. Introduction to establishing therapeutic relationships. In: Cardinal $\mathrm{P}$, Witter $\mathrm{T}$, Yamashita $\mathrm{S}$ (Eds). Navigating Medical Emergencies: An interactive Guide to Patient Management. (Establishing Therapeutic Relationships). Royal College of Physicians and Surgeons of Canada; 2020.

[19] Rawal G, Yadav S, Kumar R. Post-intensive Care syndrome: an overview. J Transl Intern Med. 2017;5(2):90-2.

[20] Nelson JE, Puntillo KA, Pronovost PJ, Walker AS, McAdam JL, Ilaoa D, et al. In their own words: patients and families define high-quality palliative care in the intensive care unit. Crit Care Med. 2010;38(3):808-18.

[21] Hart JL, Turnbull AE, Oppenheim IM, Courtright KR. Family-centered care during the COVID-19 Era. J Pain Symptom Manage. 2020. https ://doi.org/10.1016/j.jpain symma n.2020.04.017. 